\title{
Validation of an instrument to measure registered dietitians'/nutritionists' knowledge, attitudes and practices of an intuitive eating approach
}

\author{
Julie T Schaefer* and Melissa D Zullo \\ College of Public Health, Kent State University, PO Box 5190, Kent, OH 44242-001, USA
}

Submitted 25 June 2015: Final revision received 28 February 2016: Accepted 4 May 2016: First published online 1 June 2016

\begin{abstract}
Objective: The purpose of the present study was to develop and assess the construct validity of a tool to measure knowledge, attitudes and practices of registered dietitians/nutritionists $(\mathrm{RD} / \mathrm{N})$ regarding an intuitive eating lifestyle.

Design: Cross-sectional study design that utilized a survey administered to a random sample and remaining full population of $\mathrm{RD} / \mathrm{N}$.

Setting: A national survey conducted via online survey software.

Subjects: A random sample of $10 \%$ of all RD/N in the USA ( $n$ 8834) was invited to participate. Survey completion rate was $22.2 \%$ ( $n$ 1897). After initial validation, the survey was distributed to the remaining $90 \%$ of $\mathrm{RD} / \mathrm{N}$ to confirm validation.

Results: After removing items with insufficient factor loadings, results were consistent with a four-factor solution: (i) knowledge of intuitive eating; (ii) attitudes towards intuitive eating; (iii) traditional and restrictive practices; and (iv) non-restrictive and intuitive eating practices. Confirmatory factor analysis provided further evidence of the validity of the four factors and the factors had strong reliability.

Conclusions: Unlike the hypothesized three-factor solution (knowledge, attitudes and practices), validation analysis revealed that the survey measures knowledge of intuitive eating, attitudes towards intuitive eating, use of traditional and restrictive weight-management practices, and use of non-restrictive and intuitive eating practices. With the landscape of weight management and health promotion undergoing a shift towards a health centred, size acceptance approach, this instrument will provide valuable information regarding the current knowledge, attitudes and practices of $\mathrm{RD} / \mathrm{N}$ and other health promotion professionals.
\end{abstract}

Weight-related concerns, including eating disorders, disordered eating, and overweight and obesity, are prevalent in the adult population of the USA ${ }^{(1)}$. The traditional approach to weight management has been characterized by restriction of energy, specific nutrients or food groups in order to induce weight loss, and generally results in little long-term success. Studies have shown that few participants maintained any weight loss and many participants gained back more weight than was lost during the dieting period $^{(2-6)}$. Due to these negative outcomes, professionals have expressed ethical concern with the recommendation of restrictive practices for weight loss ${ }^{(4,7)}$ with some calling for a paradigm shift in the weight-management field.

One alternative, emerging approach is intuitive eating. Intuitive eating encourages individuals to focus on improving health rather than losing weight. A main focus is on use of internal cues of hunger and fullness to guide eating, with emphasis on acceptance of the body regardless of size ${ }^{(8-12)}$. The approach was developed and endorsed by two registered dietitians/nutritionists (RD/N), Evelyn Tribole and Elyse Resch, in the late 1990s. They observed that overweight clients would lose weight by following a calorie-restricted diet but almost inevitably gain the weight back over time ${ }^{(8)}$. The weight gain was often accompanied by psychological distress and feelings of guilt and failure. Through experience, Tribole and Resch found that clients who were able to adopt an intuitive eating lifestyle were able to develop a healthier psychological relationship with food, accept and respect their bodies, and stop the endless cycle of dieting and weight cycling. Over the past two decades, several research studies have investigated this lifestyle.

The intuitive eating lifestyle is associated with lower $\mathrm{BMI}^{(9,13-15)}$ and greater psychological well-being ${ }^{(9,15)}$, 
and inversely associated with eating disorder symptomato$\operatorname{logy}{ }^{(9,15)}$. Participants in intuitive eating interventions have generally lost ${ }^{(16-23)}$ or maintained ${ }^{(24-31)}$ body weight, improved cardiovascular risk irrespective of weight loss ${ }^{(25,32)}$ and increased body satisfaction ${ }^{(18,23,24,27,33-35)}$. This evidence has been coupled with a divide in the literature on the best approach to weight management ${ }^{(36)}$ and while intuitive eating research has been positive, additional studies are indicated ${ }^{(10,12)}$.

Health professionals have also been encouraging mindful eating, an approach similar to intuitive eating. Mindful eating has been described as the non-judgemental awareness of the physical and emotional sensations associated with eating or environment ${ }^{(37)}$. Mindful eating encourages individuals to eat according to internal cues of hunger and satiety ${ }^{(37)}$ and to eat slowly, taste every bite thoroughly and eat without distraction ${ }^{(38)}$. The originators of intuitive eating have acknowledged that mindful eating is part of intuitive eating ${ }^{(8)}$. Regardless of the terminology and similarities or differences between the two approaches, evidence has suggested that many dietitians may be moving away from the weight-loss paradigm and towards a size acceptance, intuitive eating approach ${ }^{(39,40)}$.

In an attempt to characterize weight-management practices that Australian dietitians use with clients, Campbell and Crawford ${ }^{(41)}$ developed a questionnaire by compiling a list of practices from the literature that was then reviewed by dietitians with expertise in weight management. In this process, dietitians were asked how frequently they performed each weight-management strategy with their clients (e.g. specific advice to reduce total fat intake) ${ }^{(41)}$. Barr and colleagues ${ }^{(40)}$ revised this questionnaire to include size acceptance philosophies (e.g. increasing self-acceptance of current weight) in their study to examine Canadian dietitians' weight-management attitudes and practices. While they have provided valuable insight into the attitudes and practices of dietitians, neither reliability nor validity of these questionnaires was established $^{(40)}$.

While two valid and reliable measures are available to capture individuals' intuitive eating behaviour, the more frequently used Tylka and Kroon van Diest's Intuitive Eating Scale- $2^{(9,15)}$ and the less common, Hawks and colleagues' Intuitive Eating Scale ${ }^{(42)}$, no such measure has been validated to gauge health professionals' knowledge, attitudes and practices regarding this approach. To date, only qualitative research has examined dietitians' knowledge of non-dieting and size acceptance approaches $^{(43)}$. As support for intuitive eating has grown, knowledge, attitudes and intuitive eating practices of $\mathrm{RD} / \mathrm{N}$ have remained unknown. Surveys are often conducted to understand human behaviour; measuring the knowledge, attitudes and practices can increase insight into a given situation ${ }^{(44)}$. Therefore, the purpose of the present study was to develop and validate a tool to measure knowledge, attitudes and practices of $\mathrm{RD} / \mathrm{N}$ regarding an intuitive eating lifestyle. Based on existing evidence, we hypothesized that this survey will reveal three valid and reliable constructs: (i) knowledge of intuitive eating; (ii) attitudes towards intuitive eating; and (iii) use of intuitive eating practices.

\section{Methods}

\section{Participants}

Contact information for all RD/N in the USA ( $n$ 88 784) was obtained from the Commission on Dietetic Registration. From this list, a $10 \%$ random sample ( $n$ 8834) was selected. The survey was distributed by email with a survey link to 8549 individuals for the initial validity testing (excluded from the $10 \%$ sample were $285 \mathrm{RD} / \mathrm{N}$ who did not provide an email address or provided an invalid email address). The survey was open for two months, June through July 2014. During this time, 1897 RD/N completed the survey for a response rate of $22.2 \%$. After initial validation analysis, the survey was distributed to the remaining $90 \%$ of $\mathrm{RD} / \mathrm{N}$ ( $n$ 79950) to confirm validity and reliability. Those in the $90 \%$ sample who indicated they worked in weight management were included in the present analysis study ( $n$ 9249). This provided a response rate of $11.6 \%$ for the validity and reliability testing. There was no incentive given for completing the survey.

\section{Procedures}

The development of the survey instrument underwent several phases. Phase I entailed the development of the original instrument by the lead investigator who is an $\mathrm{RD} / \mathrm{N}$ with training in survey methodology. Existing scales were identified and adapted and original questions were written to assess the knowledge, attitudes and practices of $\mathrm{RD} / \mathrm{N}$ relevant to intuitive eating (see 'Survey measures' for detailed description of the items). In Phase II, two nutrition professionals, who had training in the intuitive eating approach, were consulted to ensure content validity. Based on feedback, three negatively worded practice items were reworded positively to enhance clarity; one item (recommend using a food journal/diary to monitor calories, portions, etc.) was divided into two items to reflect two practices (recommend using a food journal/ diary to monitor exact calories, portions, etc. and recommend using a food journal/diary to monitor general calories, portions, etc.); and 'don't know' options were added to each of the three main sections. One of the RD/N consulted also noted that some $\mathrm{RD} / \mathrm{N}$ may be familiar with the term 'mindful eating', but not 'intuitive eating', specifically. Thus, the question 'Have you ever heard of intuitive eating?' was changed to 'Have you ever heard of intuitive or mindful eating?' for those who may use these terms interchangeably; the remainder of the survey 
referred only to intuitive eating to address the study's purpose of developing and validating a tool to measure $\mathrm{RD} / \mathrm{N}$ knowledge, attitudes and practices regarding an intuitive eating lifestyle. After these edits, an online version of the survey was created.

In Phase III, the instrument was sent to dietetic interns at Kent State University ( $n$ 13) to pilot-test the survey. Most participants were female ( $n$ 11), between 23 and 26 years of age, and all but one were non-Hispanic Caucasian. The interns completed the survey in its near final form. At the end of each section the interns were asked to provide feedback about the section they just completed and specifically to state if any items were unclear or if there were any errors. The interns indicated that all the items were clear. There was one spelling error and one error in the layout of the online survey. After these corrections, the development of the instrument was complete.

All $\mathrm{RD} / \mathrm{N}$ in the sample described above were sent an email message requesting their participation in the survey. The email asked the RD/N to follow a link to the survey website where they were first prompted to read and agree to informed consent. The survey was open for two months during which the $\mathrm{RD} / \mathrm{N}$ received the original email and two reminders to complete the survey. All procedures were reviewed and approved by the Kent State University Institutional Review Board.

\section{Survey measures}

\section{Descriptive characteristics}

Participants were asked to report their gender, age, race, highest level of education, main practice setting, state of practice, and if they had completed a certificate in paediatric or adult weight management. Participants were also asked if they had ever heard of intuitive or mindful eating and if they currently counsel overweight and/ or obese clients for weight management; if they did, the number of years' experience in this practice was requested.

\section{Practices}

Participants completed this section if they reported that they do currently counsel overweight and/or obese clients for weight management. Participants were asked to report on a Likert scale ( $0=$ 'never', $1=$ 'rarely', $2=$ 'sometimes', $3=$ 'often', $4=$ 'usually') how often they use various practices when counselling overweight and/or obese clients. This section of the survey was adapted from a tool used by Barr and colleagues ${ }^{(40)}$ to describe how often Canadian dietitians utilize several specific practices with their weight-management clients.

\section{Knowledge}

All participants completed this section. The first ten questions were adapted from the Intuitive Eating Scale-2 ${ }^{(15)}$ and described behaviours that are and are not consistent with the intuitive eating lifestyle. Questions were chosen to represent the four factors of intuitive eating (unconditional permission to eat, eating based on internal cues, eating for physical rather than emotional reasons, body-food congruence) and were reworded to reflect general knowledge about the intuitive eating lifestyle as opposed to personal behaviour. Additionally, four questions were developed to assess knowledge on current research regarding intuitive eating. These questions were developed based on findings from a recent review paper $^{(12)}$. Participants were asked to report if each statement was characteristic of an intuitive eater or if they did not know.

\section{Attitudes}

All participants completed this section. This section gauged the attitudes of $\mathrm{RD} / \mathrm{N}$ towards various health behaviours and health attitudes. These items were developed by the researcher. Items assessed attitudes towards key aspects of intuitive eating (e.g. 'It is important for individuals to learn to eat based on internal cues of hunger, fullness and satisfaction') and towards the traditional weight-loss approach (e.g. 'Weight loss should be the primary focus to improve health in overweight and/ or obese individuals'). The items favourable towards intuitive eating reflected the four factors of intuitive eating. Participants were asked to rate the degree to which they agreed or disagreed with each statement on a Likert scale (1 = 'strongly disagree', 2 = 'disagree', 3= 'neutral', $4=$ 'agree', 5 = 'strongly agree', and a 'don't know' option). Nine items were consistent with and four items were inconsistent with the intuitive eating lifestyle.

\section{Data analysis}

Since only $\mathrm{RD} / \mathrm{N}$ who worked in weight-management counselling completed the whole survey, data from this sample were used to conduct initial validity analysis. Construct validity was examined first with exploratory factor analysis (EFA) using principal axis factoring to extract factors by estimating the shared variance between items and oblique rotation of factors with promax rotation in order to allow the factors to be correlated. The correlation matrix was explored to ensure there was no singularity or multicollinearity. The number of factors was determined by examining eigenvalues and the scree plot. Items with a factor loading of at least 0.35 and a cross-loading difference of at least 0.2 were retained to create the final instrument. This analysis was repeated using data from $\mathrm{RD} / \mathrm{N}$ who did not work in weight management to ensure validity of the knowledge and attitudes factors of all $\mathrm{RD} / \mathrm{N}$.

Construct validity was further assessed through confirmatory factor analysis (CFA) with maximum likelihood estimation. Hu and Bentler ${ }^{(45)}$ have recommended several two-index strategies to assess fit, including one recommended combination of the standardized root-mean-square 
residual (SRMR) with recommended value $\leq 0.08$ and the root-mean-square error of approximation (RMSEA) with recommended value $\leq 0 \cdot 06$. Factor loadings were examined to ensure each had a loading of at least $0 \cdot 35$. Cronbach's $\alpha$ was reported to assess reliability.

\section{Results}

\section{Participants}

With regard to the initial survey distributed to the random $10 \%$ of $\mathrm{RD} / \mathrm{N}$, most participants were female (96.8\%), non-Hispanic (96.2\%) and Caucasian (91.0\%; Table 1). Nearly $44 \%$ had a Bachelor's degree while an additional $50 \cdot 2 \%$ had completed a Master's degree. Most worked in a clinical setting $(40.9 \%)$ while others worked in the community $(15 \cdot 3 \%)$, research $(6 \cdot 0 \%)$, private practice $(7 \cdot 8 \%)$ or other settings (19.7\%). Several were not practising in a dietetics-related field (10.2\%). Roughly half of the respondents reported that they work in the weight management field $(53.7 \%)$. With regard to the second distribution to the remaining $90 \%$ of $\mathrm{RD} / \mathrm{N}$, demographics were similar. Most participants were female (97.0\%),

Table 1 Sample characteristics of registered dietitians/nutritionists who completed the survey for exploratory factor analysis ( $n$ 1895)

\begin{tabular}{|c|c|c|}
\hline Variable & Mean or $n$ & SD or $\%$ \\
\hline Age (years) & 44.40 & 13.09 \\
\hline \multicolumn{3}{|l|}{ Gender } \\
\hline Male & 61 & 3.22 \\
\hline Female & 1834 & $96 \cdot 78$ \\
\hline \multicolumn{3}{|l|}{ Hispanic } \\
\hline Yes & 72 & 3.80 \\
\hline No & 1823 & $96 \cdot 20$ \\
\hline \multicolumn{3}{|l|}{ Race } \\
\hline Caucasian & 1725 & 91.03 \\
\hline African American & 45 & 2.37 \\
\hline Asian & 64 & 3.38 \\
\hline American Indian or Alaskan Native & 8 & 0.42 \\
\hline Native Hawaiian or Pacific Islander & 5 & 0.26 \\
\hline Other & 48 & 2.53 \\
\hline \multicolumn{3}{|l|}{ Education } \\
\hline Bachelor's degree & 826 & 43.59 \\
\hline Master's degree & 951 & $50 \cdot 18$ \\
\hline Doctorate degree & 83 & 4.38 \\
\hline Other & 35 & 1.85 \\
\hline \multicolumn{3}{|l|}{ Practice setting } \\
\hline Clinical & 775 & $40 \cdot 90$ \\
\hline Community & 290 & $15 \cdot 30$ \\
\hline Research or academia & 114 & 6.02 \\
\hline Private practice & 148 & $7 \cdot 81$ \\
\hline Industry & 63 & $3 \cdot 32$ \\
\hline Other & 311 & $16 \cdot 41$ \\
\hline Not currently practising as a dietitian & 194 & $10 \cdot 24$ \\
\hline \multicolumn{3}{|c|}{ Completed certificate of training in adult weight management } \\
\hline Yes & 280 & 14.78 \\
\hline No & 1615 & $85 \cdot 22$ \\
\hline \multicolumn{3}{|c|}{ Completed certificate of training in paediatric weight management } \\
\hline Yes & 110 & 5.80 \\
\hline No & 1785 & 94.20 \\
\hline \multicolumn{3}{|c|}{$\begin{array}{l}\text { Currently counsel overweight and/or obese clients for weight } \\
\text { management }\end{array}$} \\
\hline Yes & 1018 & 53.72 \\
\hline No & 877 & $46 \cdot 28$ \\
\hline
\end{tabular}

non-Hispanic (96.4\%) and Caucasian (91.9\%). About half of the RD/N had at least a Master's degree (49.2\%). Less than half of all respondents reported they worked in a clinical setting while about half $(50.3 \%)$ reported that they work in weight management.

\section{Validity and reliability}

The EFA with principal axis factoring and oblique rotation was conducted to assess construct validity. The correlation matrix was examined to ensure there was no singularity or multicollinearity. The sample size met the recommended 20:1 sample size to parameters ratio ${ }^{(46)}$. The overall KMO (Kaiser-Meyer-Olkin) was 0.88; values ranged from 0.67 to $0 \cdot 96$, which indicated acceptable sampling adequacy. The communality values were assessed to assure there was shared variance between the items. The number of factors was determined by examining eigenvalues, the scree plot and the factor solution. There were five eigenvalues greater than 1 . The scree plot inflection was between four and five factors (Fig. 1). The five-factor solution was examined first. Few items loaded on the fifth factor and of those that did, several cross-loaded with another factor. Thus, the four-factor solution was examined. The overall KMO value (0.88) and the communality values were still adequate.

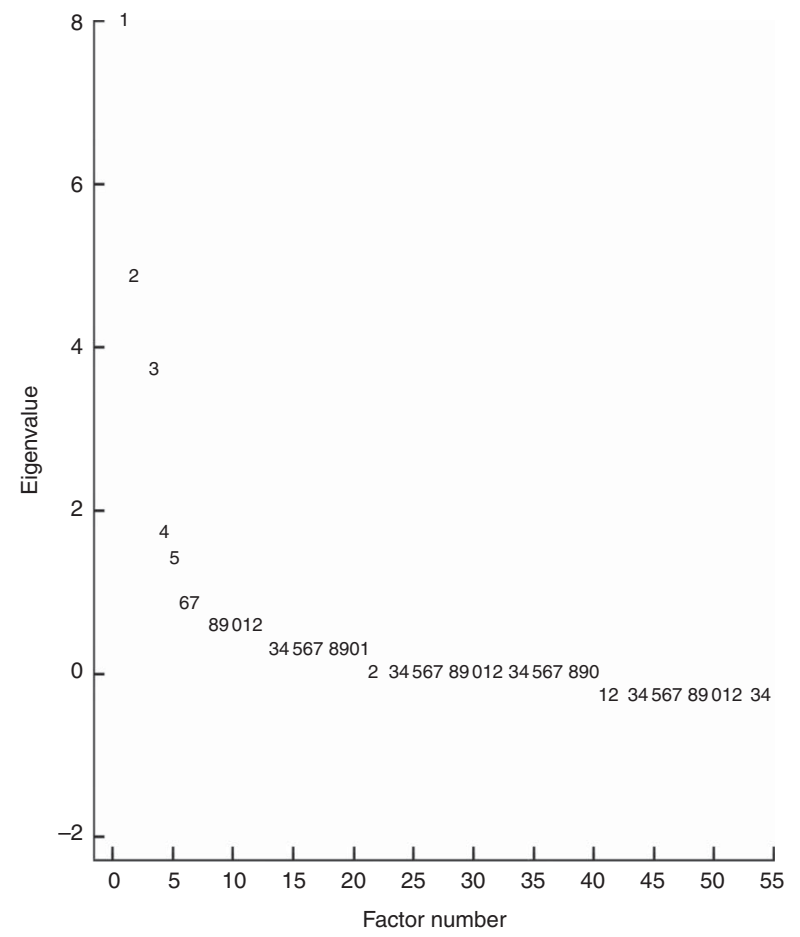

Fig. 1 Scree plot of eigenvalues obtained from exploratory factor analysis among dietitians/nutritionists (n 1895). The numbers on the figure represent the number of factors proposed. The inflection point of the graph is between four and five, suggesting that either a four- or five-factor solution would be recommended based on the results of the scree plot 
In this four-factor solution, all of the knowledge items loaded strongly with each other and were retained. Five attitude items (items 1, 6, 8, 9 and 11) that did not load on any factor (factor loading $<0 \cdot 35$ ) and three attitude items (items 2, 5 and 7) that loaded with the practice items were removed. After examination of these three items, it was apparent that the wording of these items assessed preference of a particular practice (i.e. 'To lose weight, overweight and/or obese individuals should consciously restrict calories, fat and/or carbohydrates'); thus, these items were assessed in the practices section.

The practice items loaded on to two distinct factors. Six practice items (items 4, 11, 12, 23, 24 and 25) were removed that did not load at a value of at least 0.35 on any factor. When the EFA was conducted again without these items, only two items were problematic. One practice item (item 10) did not load on the factor (factor loading <0.35) and one practice item (item 16) was cross-loading with two factors. Seven items loaded on one factor that included traditional and restrictive weight-management practices that recommend limiting calories, nutrients or eating in general, or monitoring intake and/or weight. The ten remaining practices included strategies that did not directly imply restriction (i.e. 'Work with clients using behaviour modification techniques') and strategies that promoted intuitive eating (i.e. 'Recommend keeping a hunger awareness journal/diary'). The practice items that were removed were either not specifically about eating (e.g. 'How often do you give general advice about exercise?') or were not related to one of the two approaches (non-restrictive/intuitive eating or restrictive/traditional); for example, 'How often do you recommend herbs or botanicals for weight loss?' or 'How often do you recommend a commercial or community-based weightloss programme?' These items could have been consistent with a non-restrictive/intuitive eating approach, a traditional/restrictive approach, or not consistent with either depending how these strategies were implemented.

After removal of these two items, the results indicated four distinct factors with strong factor loadings $(\geq 0.35$; Table 2) and no cross-loading (difference $>0 \cdot 20$ ). The first factor consisted of fourteen items that represent knowledge of intuitive eating. The second factor consisted of seven items that represent attitudes towards intuitive eating. The third factor consisted of ten items that represent practices consistent with a non-restrictive, intuitive eating approach, while the fourth factor consisted of seven items that represented practices consistent with a restrictive, traditional approach to weight management.

To further explore the validation of factors, the EFA was re-run in the complete sample (all $\mathrm{RD} / \mathrm{N}$, not just those who work in weight management), without the practices section of the survey, to ensure that the knowledge and attitudes factors were valid in all $\mathrm{RD} / \mathrm{N}$, not just those who work in weight management. The factor structure for knowledge and attitudes was upheld.
Next, CFA was conducted to ensure validity of the factors. Data consisted of the responses from the $9249 \mathrm{RD} / \mathrm{N}$ who completed the instrument distributed after the EFA was complete. The CFA model was specified with four factors. The RMSEA value was $0 \cdot 07$, close to the recommended value around 0.06 and less than the critical value of 0.10 that would have suggested poor fit. The SRMSR value was 0.07, indicating acceptable fit. All items loaded on their respective factor with a factor loading of at least 0.35 except for two attitude items: 'How strongly do you support the use of intuitive eating to promote a healthy lifestyle?' and 'Intuitive eating is more effective than calorie-restricted dieting for long-term weight loss and/or maintenance'. With regard to the former item, it is possible that support does not necessarily align with attitude; the latter item is a matter of evidence rather than attitude. After these two items were removed, all items loaded on their respective factors with a loading for at least $0 \cdot 35$ (Table 3). The correlations between constructs were low (Table 3), indicating little overlap between factors.

Finally, Cronbach's $\alpha$ was calculated to assess reliability of each factor (Table 3). The Cronbach's $\alpha$ value for the traditional/restrictive practices factor was 0.74 . The Cronbach's $\alpha$ value for the non-restrictive/intuitive eating practices factor was $0 \cdot 84$. The Cronbach's $\alpha$ value for the knowledge factor was 0.88 for those who work in weight management and 0.91 for the complete sample. The Cronbach's $\alpha$ value for the attitudes factor was 0.75 for those who work in weight management and 0.79 for the complete sample. While reliability was on the lower end for the traditional/restrictive practices and attitudes factors, all values indicated adequate internal reliability of the factors $^{(47)}$.

\section{Discussion}

The results indicated that, contrary to the hypothesized three factors (knowledge, attitudes and practices), the proposed instrument actually measured four distinct factors: (i) knowledge of intuitive eating; (ii) attitudes towards intuitive eating; (iii) use of restrictive and traditional weightmanagement practices; and (iv) use of non-restrictive and intuitive eating practices. All fourteen proposed knowledge items loaded strongly together. This factor measured RD/N knowledge of intuitive eating and the research regarding intuitive eating. These items were expected to load strongly together since most were adapted from a validated measure of intuitive eating behaviour ${ }^{(9,15)}$.

Originally, the authors expected the two practice factors to load on one factor in opposite directions. However, the items represented two distinct factors. One potential explanation is that $\mathrm{RD} / \mathrm{N}$ do not distinctly use one approach or the other, which would have caused the two groups of questions to load on one factor in opposite directions. $\mathrm{RD} / \mathrm{N}$ could use both approaches depending 
Table 2 Exploratory factor analysis factor loadings among registered dietitians/nutritionists who work in weight management $(n$ 1018)

\begin{tabular}{|c|c|c|}
\hline & $\begin{array}{l}\text { Knowledge of } \\
\text { intuitive eating }\end{array}$ & $\begin{array}{l}\text { Attitudes } \\
\text { toward intuit } \\
\text { eating }\end{array}$ \\
\hline $\begin{array}{l}\text { An intuitive eater tries to avoid certain foods high in fat, } \\
\text { carbohydrates or calories }\end{array}$ & 0.6272 & \\
\hline $\begin{array}{l}\text { An intuitive eater eats when feeling emotional (e.g. anxious, } \\
\text { depressed, sad), even when not physically hungry }\end{array}$ & 0.7545 & \\
\hline If craving a certain food, an intuitive eater allows his/herself to have it & 0.7077 & \\
\hline $\begin{array}{l}\text { An intuitive eater gets mad at his/herself for eating something } \\
\text { unhealthy }\end{array}$ & 0.7814 & \\
\hline $\begin{array}{l}\text { An intuitive eater is able to cope with negative emotions (e.g. anxiety, } \\
\text { sadness) without turning to food for comfort }\end{array}$ & 0.7800 & \\
\hline $\begin{array}{l}\text { An intuitive eater allows his/herself to eat what food is desired at the } \\
\text { moment }\end{array}$ & 0.6220 & \\
\hline Most of the time, an intuitive eater desires to eat nutritious foods & 0.5766 & \\
\hline $\begin{array}{l}\text { An intuitive eater mostly eats foods that make his/her body perform } \\
\text { efficiently (well) }\end{array}$ & 0.6446 & \\
\hline $\begin{array}{l}\text { An intuitive eater relies on his/her hunger signals to tell him/her when } \\
\text { to eat }\end{array}$ & 0.8848 & \\
\hline $\begin{array}{l}\text { An intuitive eater relies on his/her fullness (satiety) signals to tell him/ } \\
\text { her when to stop eating }\end{array}$ & 0.8778 & \\
\hline $\begin{array}{l}\text { Research has shown that intuitive eating is positively associated with } \\
\text { a normal BMI }\end{array}$ & 0.6373 & \\
\hline $\begin{array}{l}\text { Research has shown that weight loss is necessary for overweight } \\
\text { and/or obese individuals to improve their health }\end{array}$ & 0.4361 & \\
\hline $\begin{array}{l}\text { Research has shown that intuitive eating is positively associated with } \\
\text { psychological well-being (i.e. self-esteem, overall life satisfaction } \\
\text { and proactive coping skills) }\end{array}$ & 0.7406 & \\
\hline $\begin{array}{l}\text { Research has shown that intuitive eating is inversely (negatively) } \\
\text { associated with disordered eating, body dissatisfaction and } \\
\text { internalization of the thin ideal }\end{array}$ & 0.6081 & \\
\hline $\begin{array}{l}\text { How strongly do you support the use of intuitive eating to promote a } \\
\text { healthy lifestyle? }\end{array}$ & & 0.4792 \\
\hline $\begin{array}{l}\text { Intuitive eating is more effective than calorie-restricted dieting for } \\
\text { long-term weight loss and/or maintenance }\end{array}$ & & 0.3904 \\
\hline $\begin{array}{l}\text { It is important for individuals to learn to eat based on internal cues of } \\
\text { hunger, fullness and satisfaction }\end{array}$ & & 0.4588 \\
\hline $\begin{array}{l}\text { It is important for individuals to choose foods that honour health and } \\
\text { body function that also taste good }\end{array}$ & & 0.4380 \\
\hline Intuitive eating is an adaptive style of eating & & 0.4399 \\
\hline $\begin{array}{l}\text { Students studying to become registered dietitians should be } \\
\text { educated about intuitive eating }\end{array}$ & & 0.7825 \\
\hline Registered dietitians should be trained to use intuitive eating for & & 0.8107 \\
\hline
\end{tabular}

weight management

Give specific advice regarding opportunities for increasing incidental physical activity

Help clients find ways to be physically active that are enjoyable, rather than following a strict exercise regimen

Give advice regarding distribution of meals and snacks throughout the day

Give practical advice regarding shopping and cooking to achieve dietary goals

Help clients identify and eat foods that they enjoy and are nutritious

Work with clients using behaviour modification techniques

Help clients learn to recognize and eat based on their internal signals of hunger, fullness and satiety

Recommend keeping a hunger awareness journal/diary

Work with clients to increase self-esteem

Work with clients to increase self-acceptance of weight

Give specific advice to eat fewer calories

Give specific advice to reduce total fat intake

Advise clients to follow specific dieting plans that dictate what, when and/or how much to eat

Encourage clients to avoid foods high in fat, carbohydrates or calories

Recommend using a food journal/diary to monitor exact calories, portions, etc.

Recommend keeping a weight journal/diary

Non-restrictive/

Traditional/

Knowledge of

intuitive eating

restrictive

uitive eating practices

0.7077

0.7800

0.6220

0.5766

0.8848

0.8778

0.5458

0.6738

0.3671

0.4907

0.5765

0.5900

0.5460

0.5190

0.7831

0.7207

0.6842

0.5650

0.3860

0.4497

0.5423

0.5400

0.4964 
Table 3 Results of confirmatory factor analysis factor loadings, correlation between factors and reliability coefficients among registered dietitians/nutritionists who completed the instrument distributed after the exploratory factor analysis was complete $(n$ 9249)

\begin{tabular}{|c|c|c|c|c|c|}
\hline Item & Estimate & SE & $t$ value & Inter-construct correlations & Reliability* \\
\hline 1. Traditional/restrictive practices & 1 & 2 & 3 & 4 & 0.74 \\
\hline e1 & 0.5372 & 0.0091 & 58.9090 & 1 & \\
\hline e2 & 0.4689 & 0.0097 & $48 \cdot 1311$ & & \\
\hline e3 & 0.3952 & 0.0103 & 38.2261 & & \\
\hline e4 & 0.3854 & 0.0104 & $37 \cdot 0180$ & & \\
\hline e5 & 0.6381 & 0.0081 & 78.4890 & & \\
\hline e6 & 0.6828 & 0.0077 & $88 \cdot 7121$ & & \\
\hline e7 & 0.6009 & 0.0085 & $70 \cdot 7143$ & & \\
\hline 2. Non-restrictive/intuitive eating practices & 0.1705 & 1 & & & 0.83 \\
\hline e8 & 0.4833 & 0.0088 & $54 \cdot 8177$ & & \\
\hline e9 & 0.6266 & 0.0072 & 86.6892 & & \\
\hline e10 & 0.4258 & 0.0093 & $45 \cdot 5618$ & & \\
\hline e11 & 0.5590 & 0.0080 & 69.6836 & & \\
\hline e12 & 0.5990 & 0.0076 & $79 \cdot 2048$ & & \\
\hline e13 & 0.6751 & 0.0066 & $102 \cdot 1000$ & & \\
\hline e14 & 0.6736 & 0.0066 & 101.6000 & & \\
\hline e15 & 0.5753 & 0.0078 & 73.3805 & & \\
\hline e16 & 0.6925 & 0.0064 & 108.5000 & & \\
\hline e17 & 0.6703 & 0.0067 & $100 \cdot 4000$ & & \\
\hline 3. Knowledge & 0.0955 & -0.1517 & 1 & & 0.92 \\
\hline e18 & 0.6261 & 0.0066 & 94.3466 & & \\
\hline e19 & 0.7618 & 0.0047 & $162 \cdot 2000$ & & \\
\hline e20 & 0.6631 & 0.0061 & $107 \cdot 9000$ & & \\
\hline e21 & 0.7877 & 0.0043 & $183 \cdot 7000$ & & \\
\hline e22 & 0.7831 & 0.0044 & $179 \cdot 6000$ & & \\
\hline e23 & 0.5871 & 0.0071 & $82 \cdot 3844$ & & \\
\hline e24 & 0.5103 & 0.0080 & 63.8065 & & \\
\hline e25 & 0.6121 & 0.0068 & 89.8135 & & \\
\hline e26 & 0.8901 & 0.0026 & $345 \cdot 7000$ & & \\
\hline e27 & 0.8919 & 0.0025 & $350 \cdot 6000$ & & \\
\hline e28 & 0.5598 & 0.0075 & $75 \cdot 1526$ & & \\
\hline e29 & 0.4128 & 0.0089 & $46 \cdot 2270$ & & \\
\hline e30 & 0.6810 & 0.0059 & $115 \cdot 5000$ & & \\
\hline e31 & 0.5298 & 0.0078 & 68.0328 & & \\
\hline 4. Attitudes & 0.0963 & -0.1491 & -0.0545 & 1 & 0.75 \\
\hline e32 & 0.5453 & 0.0090 & 60.6524 & & \\
\hline e33 & 0.5678 & 0.0088 & 64.7045 & & \\
\hline e34 & 0.4465 & 0.0099 & $45 \cdot 2337$ & & \\
\hline e35 & 0.7730 & 0.0071 & $109 \cdot 3000$ & & \\
\hline e36 & 0.6731 & 0.0078 & $86 \cdot 1723$ & & \\
\hline
\end{tabular}

${ }^{*}$ Reliability values presented are Cronbach's a values for registered dietitians/nutritionists who work in weight management.

on the client. Further investigation into RD/N practices would be needed to investigate this finding. These two factors could be used to gauge how frequently RD/N who work in weight management use practices from the traditional weight-loss paradigm as well as practices that are non-restrictive and consistent with the intuitive eating approach. Measuring the two factors separately could prove to be more valuable in studying weightmanagement practices among health professionals than clustering all practices together.

According to the Academy of Nutrition and Dietetics, $\mathrm{RD} / \mathrm{N}$ are nutrition experts who translate the science of nutrition into practical solutions to help individuals make positive lifestyle changes. While support for the intuitive eating approach has grown, our understanding of $\mathrm{RD} / \mathrm{N}$ knowledge and use of this approach has not been explored until now. The present study is the first to validate a measure to assess the concept of intuitive eating. Given the current divide in the weight-management philosophies (traditional $v$. intuitive eating), it has also been unknown how favourably $\mathrm{RD} / \mathrm{N}$ view the intuitive eating lifestyle. With the validation of this survey, these gaps in the literature can now be examined.

Qualitative evidence has demonstrated that while some $\mathrm{RD} / \mathrm{N}$ maintain a focus on weight loss, many have moved towards the new paradigm that promotes concepts consistent with intuitive eating ${ }^{(39,40)}$. Other studies have assessed dietitians' attitudes towards overweight and obesity $^{(39-41,48-50)}$. The present research is the first to develop a validated measure of attitudes towards intuitive eating. Similarly, researchers have investigated dietitians' use of different weight-management practices with clients using qualitative ${ }^{(39)}$ and quantitative ${ }^{(40,41,48)}$ methods. These previous studies have been limited in that reliability and validity were not established ${ }^{(40)}$.

One strength of the present study is the large sample size as this is required for accuracy in EFA ${ }^{(46)}$. The provision of contact information by the Commission on 
Dietetic Registration enabled the researchers to collect adequate data to be able to conduct this analysis. One limitation of the study is the potential for selection bias. Participants self-selected into the study. Those who chose to participate may differ from those who chose not to participate. Since there are no population statistics on $\mathrm{RD} / \mathrm{N}$ in the USA, the degree of potential selection bias was unknown.

There are several important next steps that should follow the present study. Future research should measure convergent and discriminant validity to ensure validity of this measure. In addition, as eating- and weight-related issues continue to challenge health professionals and individuals, and as research continues to grow in favour of the intuitive eating approach, future research could use this tool to assess the knowledge, attitudes and practices regarding intuitive eating in $\mathrm{RD} / \mathrm{N}$ and other health professionals both in the USA and globally. Conducting this survey with $\mathrm{RD} / \mathrm{N}$ and other health professionals could lend insight into the current state of practice in the weight-management field. A link between research and practice is important to advance this challenging field. Further, evidence suggests that nutrition practitioners should use theoretical frameworks to enhance the effectiveness of programmes designed to address weight concerns ${ }^{(51,52)}$. This survey could be expanded to assess $\mathrm{RD} / \mathrm{N}$ application of theoretical constructs to both non-restrictive/intuitive eating and restrictive/traditional weight-management practices with clients.

\section{Conclusion}

In conclusion, the present study developed and validated an instrument to measure $\mathrm{RD} / \mathrm{N}$ knowledge of and attitudes towards intuitive eating, as well as use of traditional/ restrictive and non-restrictive/intuitive eating practices. As it has become apparent that the traditional, restrictive approach to promote weight loss is ineffective and as the support for an intuitive eating approach has grown, researchers have begun to discuss ethical issues associated with continuing to promote the use of traditional, restrictive practices for weight management ${ }^{(4,7,11)}$. In particular, Aphramor $^{(11)}$ has asserted that the ineffectiveness of the traditional energy-deficit approach to weight management has not only failed to meet standards of evidence-based practice, but has also failed to ignite a conversation about the ethical implications of continuing to use these practices and yet it continues to dominate research in the field. The tool developed and validated in the present study could help spark such a debate, by examining the current state of practice, in the hope of moving the field forward.

\section{Acknowledgements}

Acknowledgements: The authors would like to thank Amy Magnuson, PhD, RD, LD/N and Natalie Caine-Bish, PhD,
$\mathrm{RD}, \mathrm{LD} / \mathrm{N}$ for reviewing the initial survey and providing feedback. Their time and efforts are greatly appreciated. Financial support: This research received no specific grant from any funding agency in the public, commercial or not-for profit sectors. Conflict of interest: None. Authorship: J.T.S. developed and distributed the survey, conducted all data analyses, and drafted the main sections of the manuscript. M.D.Z. assisted in the conception and design of the study, supervised data collection and analysis, and contributed to and edited the introduction, discussion and conclusions. Both authors have read and approved the manuscript. Ethics of buman subject participation: This study was conducted according to the guidelines laid down in the Declaration of Helsinki and all procedures involving human subjects/patients were approved by the Institutional Review Board at Kent State University. Written informed consent was obtained from all subjects/patients.

\section{References}

1. Flegal KM, Carroll MD, Ogden CL et al. (2010) Prevalence and trends in obesity among US adults, 1999-2008. JAMA 303, 235-241.

2. Goodrick GK \& Foreyt JP (1991) Why treatments for obesity don't last. J Am Diet Assoc 91, 1243-1247.

3. Katan MB (2009) Weight-loss diets for the prevention and treatment of obesity. N Engl J Med 360, 923-925.

4. Mann T, Tomiyama AJ, Westling E et al. (2007) Medicare's search for effective obesity treatments: diets are not the answer. Am Psychol 62, 220-233.

5. Sacks FM, Bray GA, Carey VJ et al. (2009) Comparison of weight-loss diets with different compositions of fat, protein, and carbohydrates. $N$ Engl J Med 360, 859-873.

6. Wadden TA, Sternberg JA, Letizia KA et al. (1989) Treatment of obesity by very low calorie diet, behavior therapy, and their combination: a five-year perspective. Int J Obes 13, Suppl. 2, 39-46.

7. Bacon L \& Aphramor L (2011) Weight science: evaluating the evidence for a paradigm shift. Nutr J 10, 9.

8. Tribole E \& Resch E (2012) Intuitive Eating: A Revolutionary Program that Works, 3rd ed. New York: St. Martin's Press.

9. Tylka TL (2006) Development and psychometric evaluation of a measure of intuitive eating. J Couns Psychol 53, 226-240.

10. Van Dyke N \& Drinkwater EJ (2014) Relationships between intuitive eating and health indicators: literature review. Public Health Nutr 17, 1757-1766.

11. Aphramor L (2010) Validity of claims made in weight management research: a narrative review of dietetic articles. Nutr J 20, 30.

12. Schaefer JT \& Magnuson AB (2014) A review of interventions that promote eating by internal cues. J Acad Nutr Diet 114, 734-760

13. Hawks S, Madanat H, Hawks J et al. (2005) The relationship between intuitive eating and health indicators among college women. Am J Health Educ 36, 331-336.

14. Denny KN, Loth K, Eisenberg ME et al. (2013) Intuitive eating in young adults. Who is doing it, and how is it related to disordered eating behaviors? Appetite 60, 13-19.

15. Tylka TL \& Kroon Van Diest AM (2013) The Intuitive Eating Scale-2: item refinement and psychometric evaluation with college women and men. J Couns Psychol 60, 137-153. 
16. Ciampolini M, Lovell-Smith D \& Sifone M (2010) Sustained self-regulation of energy intake. Loss of weight in overweight subjects. Maintenance of weight in normal-weight subjects. Nutr Metab (Lond) 7, 4.

17. Dalen J, Smith BW, Shelley BM et al. (2010) Pilot study: Mindful Eating and Living (MEAL): weight, eating behavior, and psychological outcomes associated with a mindfulnessbased intervention for people with obesity. Complement Ther Med 18, 260-264.

18. Gagnon-Girouard MP, Begin C, Provencher V et al. (2010) Psychological impact of a 'health-at-every-size' intervention on weight-preoccupied overweight/obese women. $J$ Obes 2010, 928097.

19. Leblanc V, Provencher V, Begin C et al. (2012) Impact of a health-at-every-size intervention on changes in dietary intakes and eating patterns in premenopausal overweight women: results of a randomized trial. Clin Nutr 31, 481-488.

20. Mellin L, Croughan-Minihane M \& Dickey L (1997) The solution method: 2-year trends in weight, blood pressure, exercise, depression, and functioning of adults trained in development skills. J Am Diet Assoc 97, 1133-1138.

21. Provencher V, Begin C, Tremblay A et al. (2007) Short-term effects of a 'health-at-every-size' approach on eating behaviors and appetite ratings. Obesity (Silver Spring) 15, 957-966.

22. Timmerman GM \& Brown A (2012) The effect of a mindful restaurant eating intervention on weight management in women. J Nutr Educ Behav 44, 22-28.

23. Roughan PF, Seddon EF \& Vernon-Roberts J (1990) Long-term effects of a psychologically based group programme for women preoccupied with body weight and eating behaviour. Int J Obes 14, 135-147.

24. Bacon L, Keim NL, Van Loan MD et al. (2002) Evaluating a 'non-diet' wellness intervention for improvement of metabolic fitness, psychological well-being and eating and activity behaviors. Int J Obes Relat Metab Disord 26, 854-865.

25. Bacon L, Stern JS, Van Loan MD et al. (2005) Size acceptance and intuitive eating improve health for obese, female chronic dieters. J Am Diet Assoc 105, 929-936.

26. Cole RE \& Horacek T (2010) Effectiveness of the "My Body Knows When' intuitive-eating pilot program. Am J Health Behav 34, 286-297.

27. Ciliska D (1998) Evaluation of two nondieting interventions for obese women. West J Nurs Res 20, 119-135.

28. Katzer L, Bradshaw AJ, Horwath CC et al. (2008) Evaluation of a 'nondieting' stress reduction program for overweight women: a randomized trial. Am J Health Promot 22, 264-274.

29. Polivy J \& Herman CP (1992) Undieting: a program to help people stop dieting. Int J Eat Disord 11, 261-268.

30. Steinhardt MA, Bezner JR \& Adams TB (1999) Outcomes of a traditional weight control program and a nondiet alternative: a one-year comparison. J Psychol 133, 495-513.

31. Provencher V, Begin C, Tremblay A et al. (2009) Healthat-every-size and eating behaviors: 1-year follow-up results of a size acceptance intervention. J Am Diet Assoc 109, 1854-1861.

32. Carroll S, Borkoles E \& Polman R (2007) Short-term effects of a non-dieting lifestyle intervention program on weight management, fitness, metabolic risk, and psychological well-being in obese premenopausal females with the metabolic syndrome. Appl Physiol Nutr Metab 32, 125-142.
33. Higgins LC \& Gray W (1998) Changing the body image concern and eating behaviour of chronic dieters: the effects of a psychoeducational intervention. Psychol Health 13, 1045-1060.

34. Jackson EG (2008) Eating order: a 13-week trust model class for dieting casualties. J Nutr Educ Behav 40, 43-48.

35. Tanco S, Linden W \& Earle T (1998) Well-being and morbid obesity in women: a controlled therapy evaluation. Int J Eat Disord 23, 325-339.

36. Neumark-Sztainer D (1999) The weight dilemma: a range of philosophical perspectives. Int J Obes Relat Metab Disord 23, Suppl. 2, S31-S37.

37. Framson C, Kristal AR, Schenk JM et al. (2009) Development and validation of the mindful eating questionnaire. $\mathrm{J} \mathrm{Am}$ Diet Assoc 109, 1439-1444.

38. Singh NN, Lancioni GE, Singh AN et al. (2008) A mindfulnessbased health wellness program for an adolescent with PraderWilli syndrome. Behav Modif 32, 167-181.

39. Chapman GE, Sellaeg K, Levy-Milne R et al. (2005) Canadian dietitians' approaches to counseling adult clients seeking weight-management advice. J Am Diet Assoc 105, 1275-1279.

40. Barr SI, Yarker KV, Levy-Milne R et al. (2004) Canadian dietitians' views and practices regarding obesity and weight management. J Hum Nutr Diet 17, 503-512.

41. Campbell K \& Crawford D (2000) Management of obesity: attitudes and practices of Australian dietitians. Int $J$ Obes Relat Metab Disord 24, 701-710.

42. Hawks SR, Merrill RM \& Madanat H (2004) The intuitive eating scale: development and preliminary validation. $A m J$ Health Educ 35, 90-99.

43. Marchessault G, Thiele K, Armit E et al. (2007) Canadian dietitians' understanding of non-dieting approaches in weight management. Can J Diet Pract Res 68, 67-72.

44. Vandamme E (2009) Concepts and challenges in the use of Knowledge-Attitude-Practice surveys: literature review. Strategic Network Neglected Diseases and Zoonoses. http:// www.snndz.net/resources/literature-reviews/full-reviews/ (accessed November 2015).

45. Hu L \& Bentler PM (1999) Cutoff criteria for fit indexes in covariance structure analysis: conventional criteria versus new alternatives. Structural Equation Modeling 6, 1-55.

46. Kline R (2011) Principles and Practice of Structural Equation Modeling, 3rd ed. New York: The Guilford Press.

47. Nunnally BH \& Bernstein JC (1994) Psychometric Theory, 3rd ed. London: McGraw-Hill.

48. Harvey EL, Summerbell CD, Kirk SFL et al. (2002) Dietitians' views of overweight and obese people and reported management practices. J Hum Nutr Diet 15, 331-347.

49. McArthur LH \& Ross JK (1997) Attitudes of registered dietitians toward personal overweight and overweight clients. J Am Diet Assoc 97, 63-66.

50. Oberrieder H, Walker R, Monroe D et al. (1995) Attitude of dietetics students and registered dietitians toward obesity. J Am Diet Assoc 95, 914-916.

51. Sharma M (2007) Behavioural interventions for preventing and treating obesity in adults. Obes Rev 8, 441-449.

52. Spahn JM, Reeves RS, Keim KS et al. (2010) State of the evidence regarding behavior change theories and strategies in nutrition counseling to facilitate health and food behavior change. J Am Diet Assoc 110, 879-891. 